\title{
Surface roughness and cutting force estimation in the CNC turning using artificial neural networks
}

\author{
Mohammad Ramezani* and Ahmad Afsari
}

Department of Mechanical Engineering, College of Engineering, Shiraz Branch, Islamic Azad University, Shiraz, Iran

\begin{tabular}{l}
\hline C H R O N I C L E \\
\hline Article history: \\
Received January 2, 2015 \\
Received in revised format 6 \\
February 2015 \\
Accepted 15 February 2015 \\
Available online \\
February 172015 \\
\hline Keywords: \\
Artificial Neural Network (ANN) \\
Turning \\
Surface Roughness \\
Cutting Forces
\end{tabular}
A B S T R A C T

\begin{abstract}
Surface roughness and cutting forces are considered as important factors to determine machinability rate and the quality of product. A number of factors like cutting speed, feed rate, depth of cutting and tool noise radius influence the surface roughness and cutting forces in turning process. In this paper, an Artificial Neural Network (ANN) model was used to forecast surface roughness and cutting forces with related inputs, including cutting speed, feed rate, depth of cut and tool noise radius. The machined surface roughness and cutting force parameters related to input parameters are the outputs of the ANN model. In this work, 24 samples of experimental data were used to train the network. Moreover, eight other experimental tests were implemented to test the network. The study concludes that ANN was a reliable and accurate method for predicting machining parameters in CNC turning operation.
\end{abstract}

\section{Introduction}

Surface finish is an important factor in product quality and there are many studies to improve surface finish under various factors, but the outcomes have not seem to be satisfactory because of the complicated interactions among various factors (Groover, 2013). Many researchers have studied the estimation of surface roughness and other machining parameters at the present time; some of them have focused on experimental studies, while others have created a prediction model and only used limited number of experimental data to test the models (Childs, 2000). Cutting force is another important factor to evaluate machining machinability. It is associated with the amount of generated heat in the machining process, tool wear and surface quality (Sánchez Sola et al., 2004; Agustin et al., 2013). Some researchers have focused on the prediction of cutting forces because of its importance in the monitoring of machining systems (Sharma et al., 2008). Cutting forces influence some turning factors, such as surface quality, cutting temperature, tool wear, etc. (Rao et al., 2013). Cutting forces are directly associated with machining parameters; namely, cutting speed, feed rate, depth of cut, tool geometry 
and tool properties (Rao et al., 2013; Özel, \& Karpat, 2005). Cutting forces are generally categorized into three groups including axial force, radial force and cutting force (Rao et al., 2013).

In recent years, thanks to the technology in modern industry, manufacturers have attempted to produce high quality products with increasing production rate and decreasing production costs. There are numerous factors associated with surface roughness and cutting forces roughness (Narayanan, \& Yeldose, 2013). One of the most important factors influencing these activities are machining parameters (Childs, 2000). Cutting speed, feed rate and depth of cut have some influences on the optimum machining conditions (Jafarian et al., 2013). In machining, several parameters simultaneously influence on the desired output. In addition, implementing experimental tests is costly and takes a long time to carry them out. In order to solve these problems, prediction models can be used to find the output parameters through a change in inputs parameters (Sharma et al., 2008; Zain et al., 2010). It is hard to solve a forecasting problem and to consider all of machining parameters without using a model with the help of computer (Childs, 2000). In order to make a prediction, ANN is a powerful and reliable method in the estimation of machining process parameters (Özel et al., 2007). ANN trains to solve nonlinear problems and to extract the best output values through the use of input data. Therefore, it needs adequate inputs and outputs to train the network (Reddy et al., 2011; Zhong et al., 2006). In this article, ANN model was used to predict the machining parameters in high speed turning.

\section{Artificial Neural Networks}

Artificial Neural Networks (ANNs) train non-linear which cannot be calculated analytically (Narayanan, \& Yeldose, 2013). Many believe it is an effective method for prediction (Davalo, \& Naïm, 1991). ANN is reliable to predict the cutting parameters (Reddy et al., 2011; Zhong et al., 2006). The results in predictions of surface roughness in turning process prove the reliability and accuracy to forecast surface roughness (Childs, 2000). To predict the surface roughness and cutting forces, back propagation is a method to minimize a squared error and has the capability of connect the input and output parameters and also design non-linear relationships between them (Aleksander \& Morton, 1995). Back propagation of an artificial ANN model was trained for the given data through back propagation network following Bayesian Regulation training method. It trains the network based on Levenberg-Marquardt optimization. Bayesian regularization is a technique of minimization, which connects input and output parameters with neurons. It is a high accuracy and effective method especially when the dataset size is small (Demuth, \& Beale, 2000). Input layer get its parameters from conducted experiments, hidden layer get required information from the input layer and output layer get its required information from the ANN model (Pal et al., 2005). The number of neurons and layers are key factors to efficient use of network for solving the prediction problem (Reddy et al., 2011). In addition, the machining parameters are predicted through experimental data rather than algorithmic calculation (Ezugwu et al., 1995). The input and output dataset included 32 patterns where $75 \%$ of them are randomly selected as training data and $25 \%$ of them are randomly used to test the model. In this paper, the ANN model validates in terms of agreement with experimental results through computing the difference between actual and predicted values.

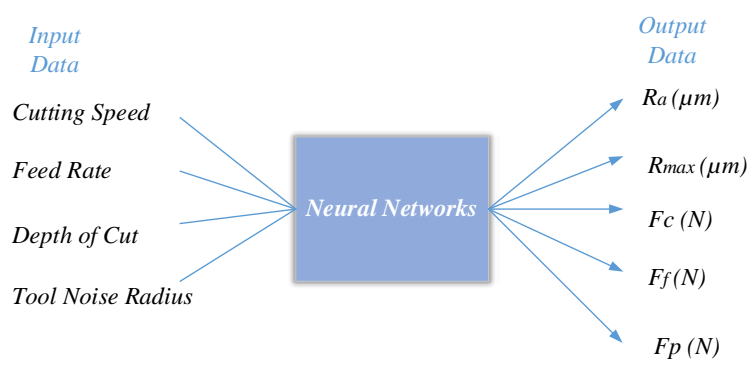

Fig. 1. ANN model

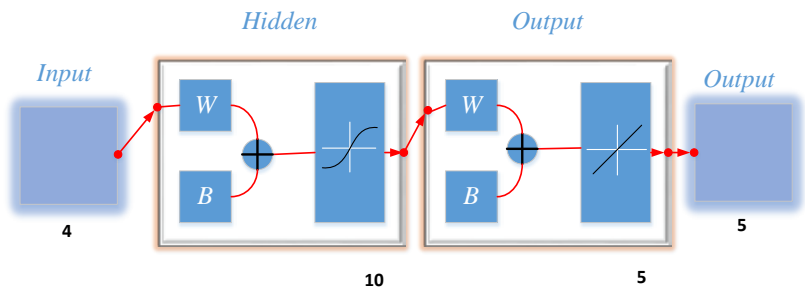

Fig. 2. Schematic diagram of ANN 


\subsection{Collection of input/output dataset}

This experiment is performed on Boeringer CNC turning machine with CBN 25 cutting tool. Roughness was measured by PERTHOMETER S8P 4.51.It can measure the values of Ra (DIN 4762, DIN 4768 and ISO 4287/1) and Rmax (DIN 4768). Three -channel KISTLER measuring device type 9257B was used to measure cutting forces. Three cutting forces were measured, including feed (axial) force (Ff), passive (radial) force (Fp) and cutting force (Fc) (Stoić, Kopač, \& Cukor, 2005).

Table 1

Measurement Results (Stoić et al., 2005)

\begin{tabular}{|c|c|c|c|c|c|c|c|c|c|}
\hline Nos. & $\mathrm{v}_{\mathrm{c}}(\mathrm{m} / \mathbf{m i n})$ & $a_{p}(\mathbf{m m})$ & $\mathrm{f}(\mathrm{mm})$ & $\mathbf{r}_{\mathrm{c}}(\mathrm{mm})$ & $\mathbf{R}_{\mathbf{a}}(\boldsymbol{\mu m})$ & $R_{\max }(\mu \mathrm{m})$ & $F_{c}(N)$ & $\mathrm{F}_{\mathrm{f}}(\mathrm{N})$ & $F_{p}(N)$ \\
\hline 1 & 600 & 0.2 & 0.1 & 0.4 & 0.96 & 4.9 & 5.86 & 14.49 & 47.98 \\
\hline 2 & 450 & 0.35 & 0.1 & 0.4 & 1.44 & 7.38 & 115.201 & 27 & 65.43 \\
\hline 3 & 450 & 0.2 & 0.2 & 0.4 & 2.03 & 8.65 & 61 & 17.57 & 65.76 \\
\hline 4 & 600 & 0.2 & 0.2 & 0.4 & 1.76 & 7.54 & 60.650 & 15.6 & 70.06 \\
\hline 5 & 450 & 0.35 & 0.2 & 0.4 & 2.24 & 10.02 & 124.81 & 28.16 & 87.51 \\
\hline 6 & 600 & 0.35 & 0.2 & 0.4 & 1.97 & 8.91 & 123.41 & 26.15 & 91.80 \\
\hline 7 & 450 & 0.2 & 0.1 & 1.2 & 0.69 & 4.34 & 57.9 & 29.18 & 46.63 \\
\hline 8 & 450 & 0.35 & 0.1 & 1.2 & 0.9 & 5.71 & 121.66 & 39.70 & 68.32 \\
\hline 9 & 600 & 0.35 & 0.1 & 1.2 & 0.63 & 4.6 & 121.3 & 37.75 & 72.67 \\
\hline 10 & 600 & 0.2 & 0.2 & 1.2 & 1.22 & 5.96 & 67.3 & 28.23 & 73 \\
\hline 11 & 450 & 0.35 & 0.2 & 1.2 & 1.71 & 8.34 & 131.37 & 40.74 & 90.45 \\
\hline 12 & 600 & 0.35 & 0.2 & 1.2 & 1.44 & 7.23 & 130.94 & 38.0 .970 & 94.74 \\
\hline 13 & 375 & 0.275 & 0.15 & 0.8 & 1.37 & 6.92 & 91.54 & 29.97 & 62.65 \\
\hline 14 & 525 & 0.125 & 0.15 & 0.8 & 0.96 & 5.1 & 33.6 & 17.15 & 48.22 \\
\hline 15 & 525 & 0.275 & 0.05 & 0.8 & 0.35 & 2.44 & 6.97 & 16.93 & 58.53 \\
\hline 16 & 525 & 0.275 & 0.25 & 0.8 & 1.69 & 7.31 & 100.27 & 29.25 & 92.69 \\
\hline 17 & 525 & 0.275 & 0.15 & 0.4 & 1.44 & 6.79 & 68.86 & 21.43 & 59.15 \\
\hline 18 & 525 & 0.275 & 0.15 & 0.8 & 0.89 & 4.65 & 89.77 & 28.76 & 72 \\
\hline 19 & 525 & 0.275 & 0.15 & 0.8 & 0.9 & 4.72 & 90.789 & 27.88 & 73.03 \\
\hline 20 & 525 & 0.275 & 0.15 & 0.8 & 0.89 & 4.67 & 90.904 & 27.67 & 73.31 \\
\hline 21 & 525 & 0.275 & 0.15 & 0.8 & 0.87 & 4.58 & 92.11 & 29.04 & 71.97 \\
\hline 22 & 525 & 0.275 & 0.15 & 0.8 & 0.88 & 4.63 & 90.87 & 28.52 & 72.22 \\
\hline 23 & 525 & 0.275 & 0.15 & 0.8 & 0.89 & 4.7 & 88.917 & 28.77 & 71.88 \\
\hline 24 & 525 & 0.275 & 0.15 & 0.8 & 0.88 & 4.66 & 89.984 & 28.04 & 72.11 \\
\hline
\end{tabular}

Table 2

Testing the network with eight new samples

\begin{tabular}{lcccccccc}
\hline & Sample 1 & Sample 2 & Sample 3 & Sample 4 & Sample 5 & Sample 6 & Sample 7 & Sample 8 \\
\hline $\mathrm{v}_{\mathrm{c}}(\mathrm{m} / \mathrm{min})$ & 450 & 600 & 600 & 450 & 675 & 525 & 525 & 525 \\
$\mathrm{a}_{\mathrm{p}}(\mathrm{mm})$ & 0.2 & 0.35 & 0.2 & 0.2 & 0.275 & 0.425 & 0.275 & 0.275 \\
$\mathrm{f}(\mathrm{mm})$ & 0.1 & 0.1 & 0.1 & 0.2 & 0.15 & 0.15 & 0.15 & 0.15 \\
$\mathrm{r}_{\mathrm{c}}(\mathrm{mm})$ & 0.4 & 0.4 & 1.2 & 1.2 & 0.8 & 0.8 & 1.2 & 0.8 \\
Actual $\mathrm{R}_{\mathrm{a}}(\mu \mathrm{m})$ & 1.22 & 1.77 & 0.42 & 1.49 & 0.65 & 1.39 & 0.51 & 0.91 \\
Predicted $\mathrm{R}_{\mathrm{a}}(\mu \mathrm{m})$ & 1.0507 & 1.2572 & 0.4085 & 1.3748 & 0.6204 & 1.2911 & 0.7435 & 0.9998 \\
\% error & 16.1131 & 40.7891 & 2.8152 & 8.3794 & 4.7711 & 7.6601 & -31.4055 & -12.0879 \\
Actual $\mathrm{R}_{\max }(\mu \mathrm{m})$ & 6.02 & 6.27 & 3.23 & 6.98 & 3.96 & 7.83 & 3.52 & 5.06 \\
Predicted $\mathrm{R}_{\max }(\mu \mathrm{m})$ & 5.6594 & 5.6402 & 2.9474 & 6.9606 & 3.1012 & 6.2398 & 3.7632 & 4.7042 \\
\% error & 6.3717 & 11.1663 & 9.5881 & 0.2787 & 27.6925 & 25.4848 & -6.4626 & 7.5635 \\
Actual $\mathrm{F}_{\mathrm{c}}(\mathrm{N})$ & 51.24 & 114.785 & 57.52 & 67.68 & 90.87 & 131.4 & 92.8 & 89.012 \\
Predicted $\mathrm{F}_{\mathrm{c}}(\mathrm{N})$ & 57.3962 & 108.9980 & 49.1417 & 64.1331 & 84.516 & 176.7559 & 95.7348 & 90.8908 \\
\% error & -10.7258 & 5.3093 & 17.0493 & 5.5305 & 7.5181 & -25.6602 & -3.0656 & -2.0671 \\
Actual & 16.42 & 25.09 & 27.16 & 30.54 & 24.86 & 28.33 & 34.8 & 28.9 \\
Predicted $\mathrm{Ff}(\mathrm{N})$ & 17.1608 & 28.1702 & 27.1943 & 28.1553 & 22.0052 & 40.3933 & 34.9859 & 28.3854 \\
\% error & -4.3168 & -10.9342 & -0.1261 & 8.4698 & 12.9733 & -29.8646 & -0.5314 & 1.8129 \\
Actual $\mathrm{F}_{\mathrm{p}}(\mathrm{N})$ & 43.68 & 69.72 & 50.92 & 68.71 & 54.18 & 91.70 & 72.08 & 72.08 \\
Predicted $\mathrm{F}_{\mathrm{p}}(\mathrm{N})$ & 42.1502 & 71.9690 & 52.0851 & 67.4787 & 56.7958 & 93.3550 & 73.8460 & 72.4961 \\
\% error $\mathrm{F}_{\mathrm{p}}(\mathrm{N})$ & 3.6294 & -3.1250 & -2.2369 & 1.8247 & -4.6056 & -1.7728 & -2.3915 & -0.5740 \\
\hline
\end{tabular}


The work piece material is steel 40CrMnMo7 (W. No. 1.2311).It uses for moulds which have many applications in industry. It is a good polishable material and It can work in a high temperature condition (850-1050 $0 \mathrm{C}$ ). A bar with $60 \mathrm{~mm}$ long and 200mm diameter with the average hardness 45-47HRC was prepared for each sample (Stoić et al., 2005).

As Table 1 indicates, 24 number of tests with different cutting forces, feed rate, depth of cut and tool radius noise were applied. For each sample, the value of Ra, R max, Fc, Fp and Ff were measured. Then these values were used as training dataset for artificial neural network. Finally, eight other experiments with random inputs were conducted for testing the reliability of ANN model

\section{Results}

Mean Squared Error (MSE) between network outputs and target values is used in ANN's model. At first, the maximum number of 1000 epochs was set to stop the training, but after 207 iterations it was terminated because there was no progress in the achieved MSE. As illustrated in Fig. 3, the best training performance is 0.061505 at epoch 80 , which is a low prediction error measured with MSE.

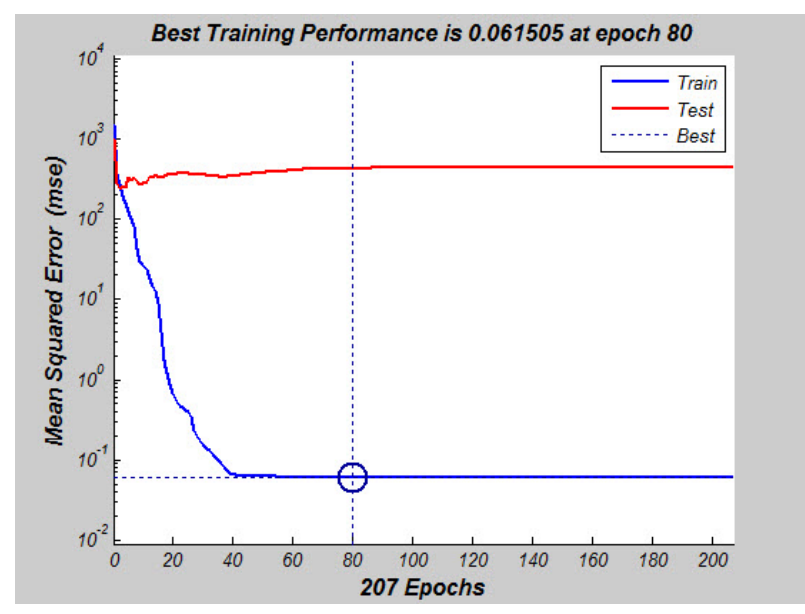

Fig. 3. Mean Square Error-Number of Epochs
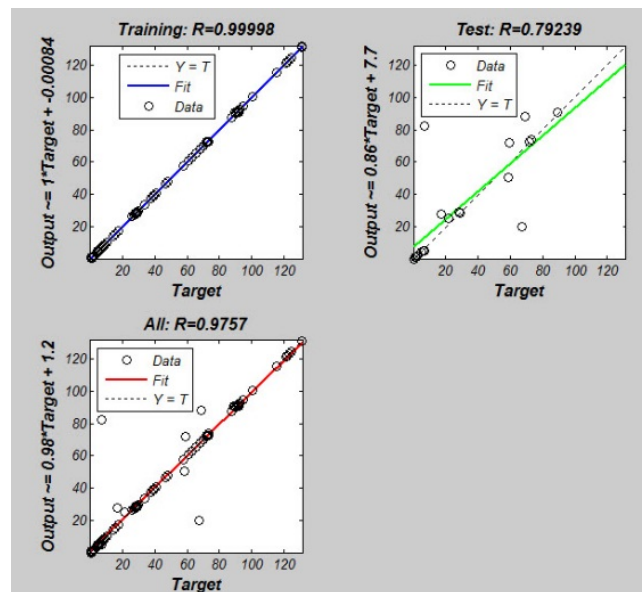

Fig. 4. Correlation Coefficient (Targets-Outputs)

Correlation Coefficient $(\mathrm{R})$ is performance measure relation strength between experimental and predicted values. As presented in Fig. 4, their values are close together. Error histogram is depicted in Fig. 5.

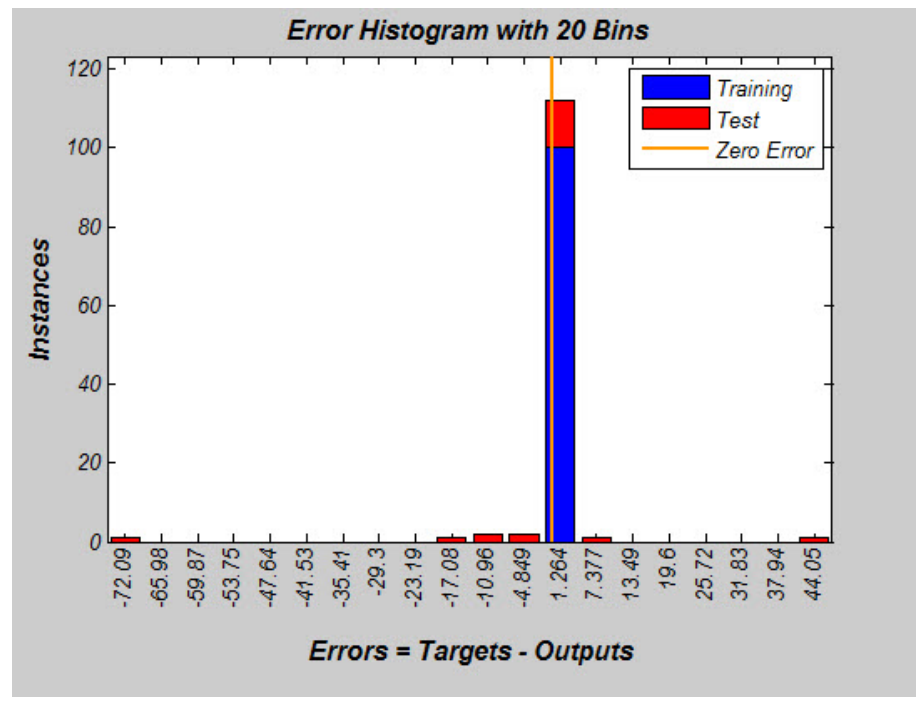

Fig. 5. Error Histogram results simulation 
It is based on [actual output-predicted output]. Zero point is the minimum point in which the possibility of error lies. The large peak at zero point means small difference between experimental outputs and predicted values; however, small peak shows incorrect values. Moreover, it reveals the large difference between output data and predicted output. Fig. 6 to Fig. 10 show the difference between actual and predicted values for eight samples to show the amount of error in using ANN method.

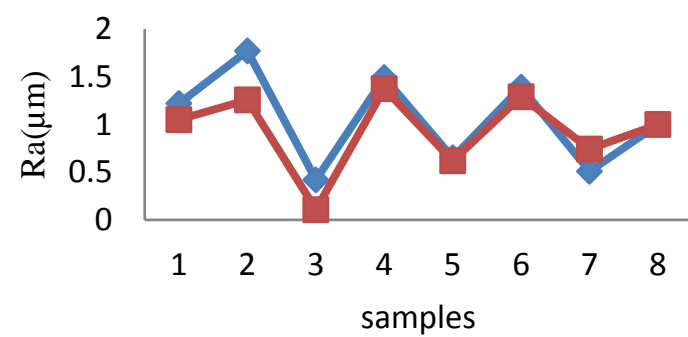

$\sim$ Actual $\operatorname{Ra}(\mu \mathrm{m}) \quad \longrightarrow$ Predicted $\operatorname{Ra}(\mu \mathrm{m})$

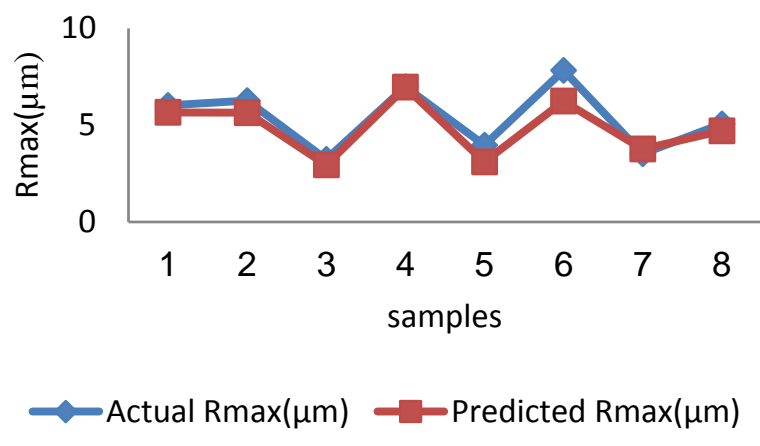

Fig. 7. Comparison of Rmax values obtained from actual measurements and ANN method-(sample No. Vs $\operatorname{Rmax}(\mu \mathrm{m}))$

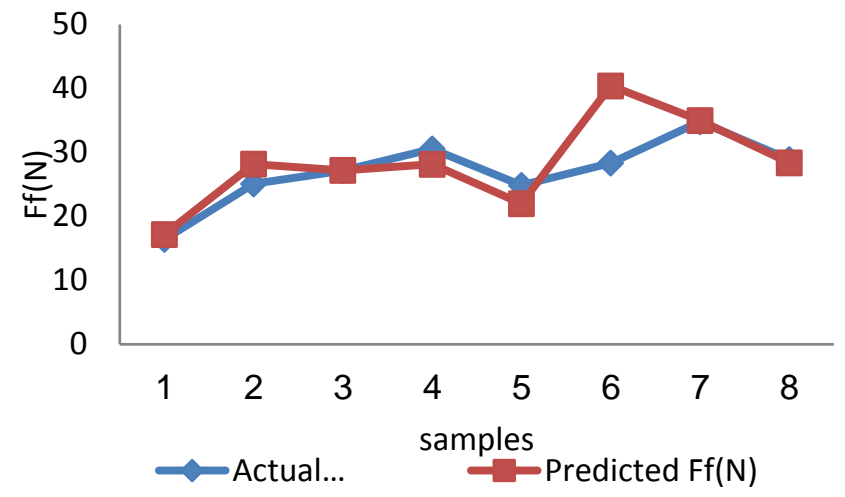

Fig. 9. Comparison of $\mathrm{Ff}$ values obtained from actual measurements and ANN method-(sample No. $\operatorname{Vs} \operatorname{Ff}(\mathrm{N}))$ actual measurements and ANN method-(sample No. Vs Fc(N))

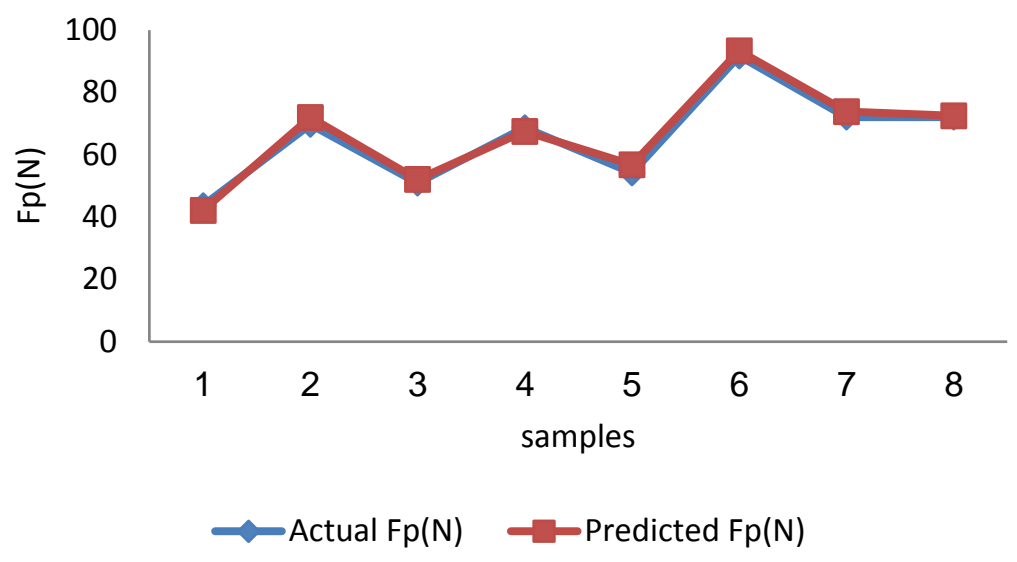

Fig. 10 Comparison of Fp values obtained from actual measurements and ANN method-(sample No. Vs Newton) 


\section{Conclusion}

We have predicted the surface roughness and cutting forces for CNC turning using ANN with four inputs. These included turning speed, feed rate, depth of cut and tool noise radius. The reliability of network was tested and observed by finding the error percentage between data from eight new samples and predicted data.

\section{References}

Agustin, B., Bernal, C., Camacho, A.M., \& Rubio, E.M. (2013). Experimental Analysis of the Cutting Forces Obtained in Dry Turning Processes of UNS A97075 Aluminium Alloys. Procedia Engineering, 63, 694-699

Aleksander, I., \& Morton, H. (1995). An introduction to neural computing. London: International Thomson Computer Press.

Childs, T. (2000). Metal machining: Theory and applications. London: Arnold.

Davalo, E., \& Naïm, P. (1991). Neural networks. London: Macmillan.

Demuth, H., \& Beale, M. (2000). Matlab Neural Network Toolbox User's Guide.

Ezugwu, E. O., Arthur, S. J., \& Hines, E. L. (1995). Tool-wear prediction using artificial neural networks. Journal of Materials Processing Technology, 49, 255-264.

Groover, M. P. (2002). Solutions manual: fundamentals of modern manufacturing. Wiley.

Jafarian, F., Taghipour, M., \& Amirabadi, H. (2013). Application of artificial neural network and optimization algorithms for optimizing surface roughness, tool life and cutting forces in turning operation. Journal of Mechanical Science and Technology, 27, 1-9

Narayanan, N., \& Yeldose, B. C. (2013). Prediction of surface roughness using ANN in turning. International Journal of Merging Technology and Advanced Engineering, 3(4).

Özel, T., Karpat, Y., Figueira, L., \& Davim, J. P. (2007). Modelling of surface finish and tool flank wear in turning of AISI D2 steel with ceramic wiper inserts. Journal of materials processing technology, 189(1), 192-198.

Özel, T., \& Karpat, Y. (2005). Predictive modeling of surface roughness and tool wear in hard turning using regression and neural networks. International Journal of Machine Tools and Manufacture, 45(4), 467-479.

Pal, S. K., \& Chakraborty, D. (2005). Surface roughness prediction in turning using artificial neural network. Neural Computing \& Applications, 14(4), 319-324.

Rao, C. J., Rao, D. N., \& Srihari, P. (2013). Influence of cutting parameters on cutting force and surface finish in turning operation. Procedia Engineering, 64, 1405-1415.

Reddy, V. D., Krishnaiah, G. A., Kumar, H., \& Priya, S. K. (Dec., 2011). ANN Based Prediction of Surface Roughness in Turning. International Conference on Trends in Mechanical and Industrial Engineering (ICTMIE'2011) Bangkok

Sánchez Sola, J.M., Marcos, M., Sebastián, M.A., Sánchez, M., \& González, J.M. (2004). Modelo paramétrico de la Fuerza de corte para el torneado de la aleación AA2024. Boletín de la Sociedad Española. Cerámica y vidrio, 43(2), 179-181.

Sharma, V. S., Dhiman, S., Sehgal, R., \& Sharma, S. K. (2008). Estimation of cutting forces and surface roughness for hard turning using neural networks. Journal of Intelligent Manufacturing, 19(4), 473-483.

Stoić, A., Kopač, J., \& Cukor, G. (2005). Testing of machinability of mould steel 40CrMnMo7 using genetic algorithm. Journal of materials processing technology, 164, 1624-1630.

Zain, A. M., Haron, H., \& Sharif, S. (2010). Prediction of surface roughness in the end milling machining using Artificial Neural Network. Expert Systems with Applications, 37(2), 1755-1768.

Zhong, Z. W., Khoo, L. P., \& Han, S. T. (2006). Prediction of surface roughness of turned surfaces using neural networks. The International Journal of Advanced Manufacturing Technology, 28(78), 688-693. 